2013-6

\title{
Advanced Deepwater Monitoring System
}

\author{
David Brower \\ Astro Technology \\ John Hedengren \\ Brigham Young University, john.hedengren@byu.edu \\ Reza Asgharzadeh Shishavan \\ Brigham Young University \\ Alexis Brower \\ Astro Technology
}

Follow this and additional works at: https://scholarsarchive.byu.edu/facpub

Part of the Chemical Engineering Commons

\section{Original Publication Citation}

Brower, David, et al. "Advanced deepwater monitoring system." ASME 2013 32nd International Conference on Ocean, Offshore and Arctic Engineering. American Society of Mechanical Engineers, 2013.

\section{BYU ScholarsArchive Citation}

Brower, David; Hedengren, John; Asgharzadeh Shishavan, Reza; and Brower, Alexis, "Advanced Deepwater Monitoring System" (2013). Faculty Publications. 1711.

https://scholarsarchive.byu.edu/facpub/1711

This Peer-Reviewed Article is brought to you for free and open access by BYU ScholarsArchive. It has been accepted for inclusion in Faculty Publications by an authorized administrator of BYU ScholarsArchive. For more information, please contact ellen_amatangelo@byu.edu. 


\section{OMAE2013/10920}

\section{ADVANCED DEEPWATER MONITORING SYSTEM}

\author{
David Brower* \\ Astro Technology, Inc. \\ 712 Main Street, Suite 3200 \\ Houston, Texas 77002 \\ Email: dbrower@astrotechnology.com
}

Reza Asgharzadeh Shishivan

Department of Chemical Engineering

350 Clyde Building

Brigham Young University

Provo, Utah 84602

Email: rasgharzadeh@astrotechnology.com

\author{
John D. Hedengren \\ Department of Chemical Engineering \\ 350 Clyde Building \\ Brigham Young University \\ Provo, Utah 84602 \\ Email: john.hedengren@byu.edu
}

\section{ABSTRACT}

This study investigates new methods to improve deepwater monitoring and addresses installation of advanced sensors on "already deployed" risers, flowlines, trees, and other deepwater devices. A major shortcoming of post installed monitoring systems in subsea is poor coupling between the sensor and structure. This study provided methods to overcome this problem. Both field testing in subsea environments and laboratory testing were performed. Test articles included actual flowline pipe and steel catenary risers up to twenty-four inches in diameter. A monitoring device resulting from this study can be installed in-situ on underwater structures and could enhance productivity and improve safety of offshore operations. This paper details the test results to determine coupling methods for attaching fiber optic sensor systems to deepwater structures that have already been deployed. Subsea attachment methods were evaluated in a forty foot deep pool by divers. Afterword, structural testing

\footnotetext{
*Address all correspondence to this author.
}

was conducted on the systems at the NASA Johnson Space Center. Additionally a 7,000 foot deep sensor station was attached to a flowline with the aid of a remote operated vehicle. Various sensor to pipe coupling methods were tested to measure tensile load, shear strength and coupling capability. Several adhesive bonding methods in a subsea environment were investigated and subsea testing yielded exceptionally good results. Tensile and shear properties of subsea application were approximately 80 percent of those values obtained in dry conditions. Additionally, a carbide alloy coating was found to increase the shear strength of metal to metal clamping interface by up to 46 percent. This study provides valuable data for assessing the feasibility of developing the next generation fiber optic sensor system that could be retrofitted onto existing subsea pipeline structures.

\section{NOMENCLATURE}

A Cross-Sectional Area of Tendon $\left(\mathrm{m}^{2}\right)$

$C T E_{S}$ Coefficient of Thermal Expansion for Pipe 


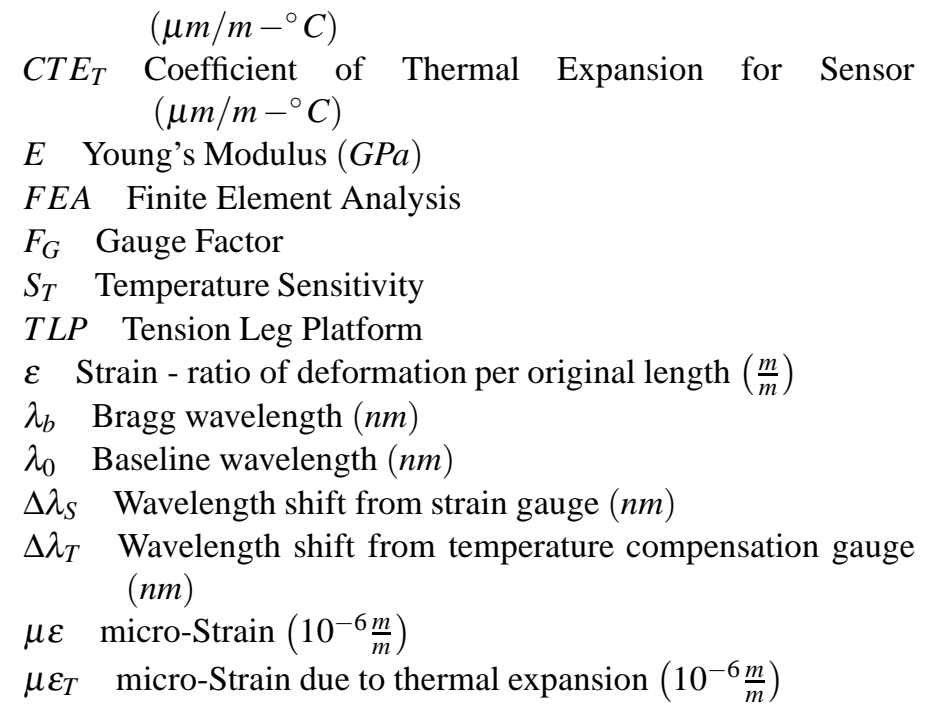

\section{FIBER OPTIC LOAD SENSORS}

This project details a new innovation to replace Tension Leg Platform (TLP) load monitoring systems that use load cells, with fiber optic load advanced sensors that are installed on the tendons. This project involved several innovations including postinstalled subsea load sensing with fiber optics, laboratory testing of the adhesive and sensor strength in sub-sea conditions, and verification of sensor adhesion through bend, tension, and compression cycling up to $70 \%$ of ASTM A36 steel yield strength. The newly installed load sensors are a first of its kind innovation that is in actual operation.

Much progress has been made in the last decade to monitor subsea operations. Critical parameters such as stress, strain, temperature, pressure, vibration, leaks, and flow assurance issues are of great interest. The first subsea fiber optic sensing system was installed as part of the Troika project in the Gulf of Mexico in 1997. Troika used Fiber Bragg Grating (FBG) sensors with a very early and elementary signal conditioning unit. This early project was tasked to monitor the pressure without placing any penetrations into the 14 mile pipe-in-pipe subsea tieback. In addition to pressure, the temperature and strain were monitored in real time. Since then other deployments utilizing fiber optic sensors were deployed on deepwater drilling risers and later on deepwater steel cantenary risers [1-5]. An important aspect is that the sensors do not require penetrations into the flow stream, pressure vessel, or pipe wall. The sensors use light to interrogate the fiber optic measurement devices so no electric current is required. The sensors can be installed many miles away with little attenuation of the signal strength. The fiber optic strands themselves are vulnerable to damage so they are ruggedized with multiple layers of protective sheathing for installation and long-term service. Monitoring of subsea pipelines and structures provides needed information for managing offshore oil and gas operations and helps prevent environmental damage and catastrophic failure.

Another aspect of this project is in the analysis, display, and dissemination of results for early fault detection. When retrofitted measurement devices are installed on existing subsea equipment, fatigue life must take into account prior information that is not typically available. This study employs methods for extrapolating fatigue life to estimate the prior unknown operating data. Vibration analysis and strain are used to predict time to failure. Temperature, pressure, strain, and other non-penetrating sensors are used to predict flow assurance. Dynamic data reconciliation is used to align the observed measurements with detailed process mathematical models of the system. The software complements the measurement devices to synthesize and deliver real-time process information to operators, engineers, and management. Web-based streaming of the results from the production facility allows world-wide access to current conditions and summary reports.

\section{TESTING OF LOAD SENSORS}

Three fully integrated test articles were used for the laboratory tests and consisted of three 24" diameter test pipes with two nominally 36 " long segments and one nominally 14' long segment. The two 36" test articles consisted of steel (ASTM A232 steel for the ends and ASTM A36 steel for the mid-section). The manufactured fiber optic sensor stations were integrated with the pipes for each of the above test articles (see Figure 1), with a combination of friction and adhesive attachments. All of the fiber optic sensors were integrated with the software monitoring system to collect data at two samples per second for each of the sensors in raw format and calculated results for strain and temperature.

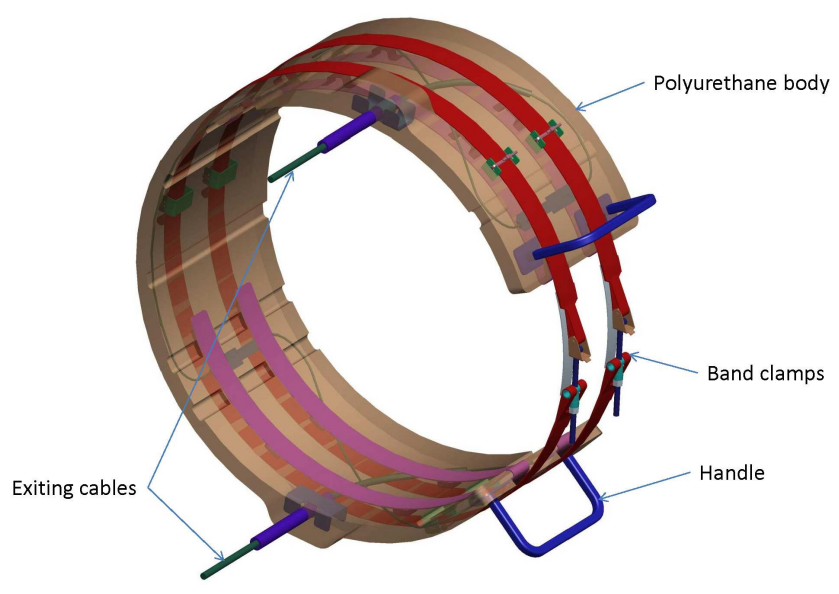

FIGURE 1. CLAMP AND FIBER OPTIC SENSOR STATIONS. 
Each of the test articles were constructed to emulate the configuration of the TLP clamp system. Preparation of surface bonding included cleaning, grinding, and bonding. Bonding was performed in a simulated subsea environment with the aid of a small water pool. Resistive strain gauges were bonded directly to surface of the steel to verify the fiber optic strain sensor readings. After the attached sensors were installed, a repeat stress analysis was conducted with a two mil thick coating of polyurethane between the sensor and the bare steel pipe. This testing was to ensure that time and temperature shift factors were included to determine stress relaxation modulus effect of the polymer layer. A 70\% of yield stress was achieved and stress relaxation modulus occurred from zero time to one month of constant stress loading. This analysis compared the elastic region of the carbon steel to the viscoelastic properties of the polyurethane coating.

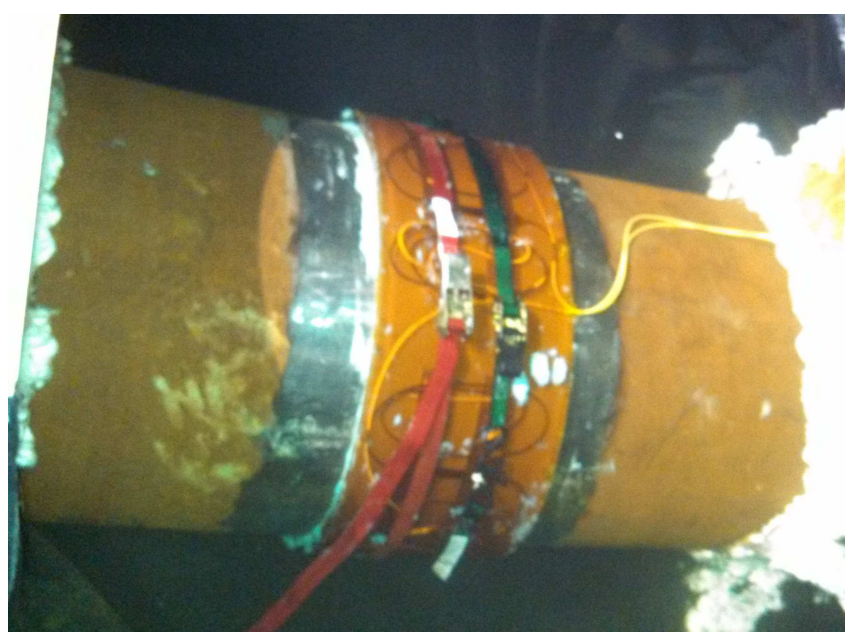

FIGURE 2. INSTALLED CLAMP AND FIBER OPTIC SENSOR STATIONS.

To test the functionality of the monitoring system, sensor stations were installed on the test article pipes as shown in Figure 2 (with the same type and dimensions as the actual tendons) and were tested under bending, tension and compression conditions. Each sensor station consisted of four sets of sensors which were placed on 0, 90, 180 and 270 angle degrees along the cross section of the pipe. Each sensor set consisted of one strain and one temperature compensation sensor. Temperature compensation accounts for changes in the reported strain due to the temperature effect on the fiber optic cable, thermal expansion of the base material, and thermal expansion of the optic sensor. These tests were performed at a facility in Houston, Texas.

\section{SIMULATION OF LOAD TESTING}

A Finite Element Analysis (FEA) was conducted to ensure that the test samples would be able to withstand the test loads without failure and to distribute the stress evenly across the simulated tendon. A number of designs were evaluated to ensure an even distribution of strain under tension as shown in Figure 3 for the two 36" test samples as shown in Figure 3.

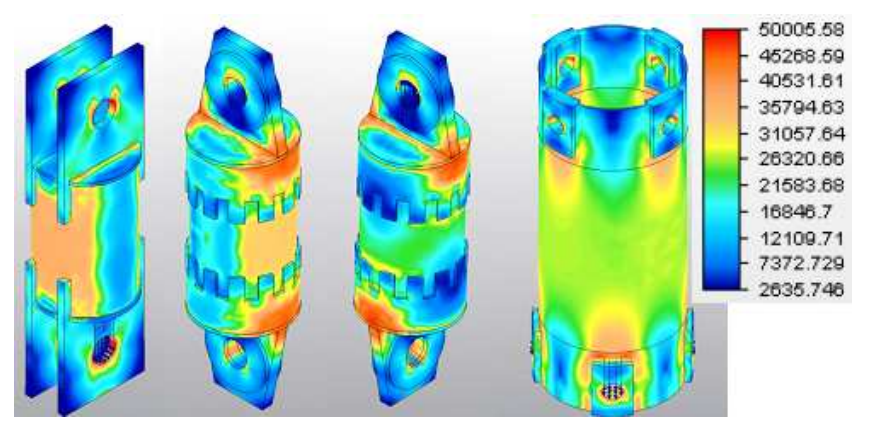

FIGURE 3. SUCCESSIVE DESIGNS FROM LEFT (INITIAL) TO RIGHT (FINAL) FOR THE TENSION TESTING.

Red indicates stress up to $50 \mathrm{ksi}\left(50,000 \frac{\mathrm{lbf}}{\mathrm{in}^{2}}\right)$ which would cause inelastic deformation. The final design on the right in Figure 3 showed a more even distribution of tension with fewer potential local failure points. The objective of the FEA was to verify a design that could provide a uniform tension or compression up to $70 \%$ of failure. The end caps are ASTM A232 steel with a yield strength of $50 \mathrm{ksi}$ and the midsection is ASTM A36 with a yield strength of $36 \mathrm{ksi}$. The FEA of the first three designs revealed non-uniform loading and potential for inelastic deformation. The final design (far right) showed uniform loading of approximately $25 \mathrm{ksi}$, which is approximately $70 \%$ of yield.

The FEA was also conducted for the compressive loading, although it was expected that there would be a more even distribution of stress under compression because of the ability to apply a consistent load at the end caps that would distribute evenly across the load specimen. The results of the stress analysis are shown in Figure 4.

The final design confirms that there is uniform distribution of strain at the sensor location under compression with uniform stress of approximately $25 \mathrm{ksi}$. With ASTM A36 steel, $25 \mathrm{ksi}$ is $70 \%$ of yield (36 ksi).

A similar analysis was conducted for the 4-point bending tests. The purpose of the bending test was to confirm the fiber optic sensor performance under lateral strain. Combined with the prior two tests on compression and tension, the bending test confirms sensor performance under three principle modes that may be encountered with the TLP sensor stations (see Figure 5). 


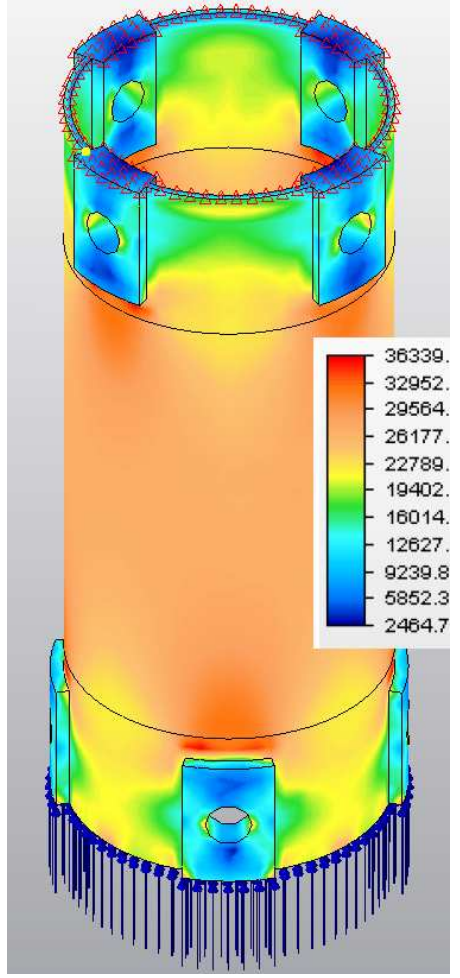

FIGURE 4. SIMULATION OF THE COMPRESSIVE LOADING ON THE 36" TEST SPECIMEN.

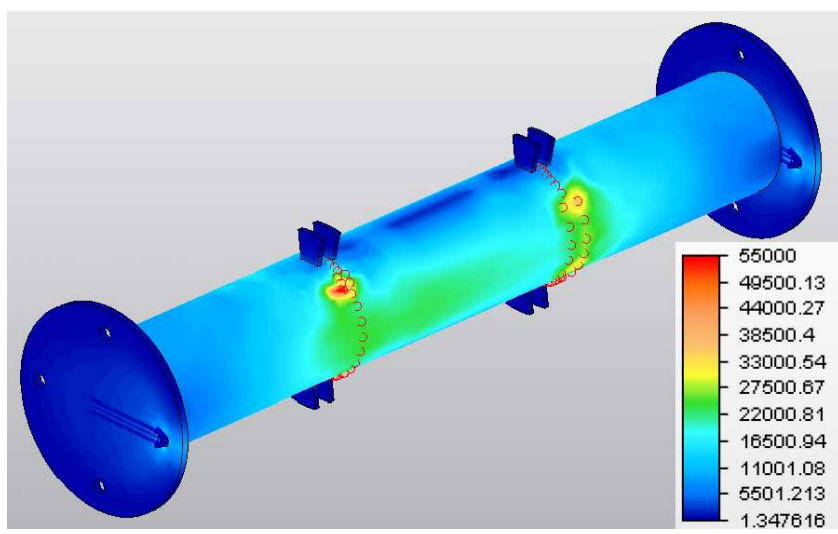

FIGURE 5. SIMULATION OF THE 4-POINT BENDING TEST.

Figure 5 shows the anticipated areas of high strain. Sensors were placed at $0,90,180$, and 270 degree azimuth to detect strain for all bending modes of the article.

\section{DATA ACQUISITION AND ANALYSIS}

Data acquisition software was designed which was based on the data collected from an optical sensing module and was updated at the frequency of $2 \mathrm{~Hz}$ that was optimized to allow a sufficiently strong source signal and capture the appropriate system dynamics. Measurements were returned to the optical sensor as a range of magnitudes over a limited frequency. Individual measurements were characterized by peaks in the power spectrum as shown in Figure 6.

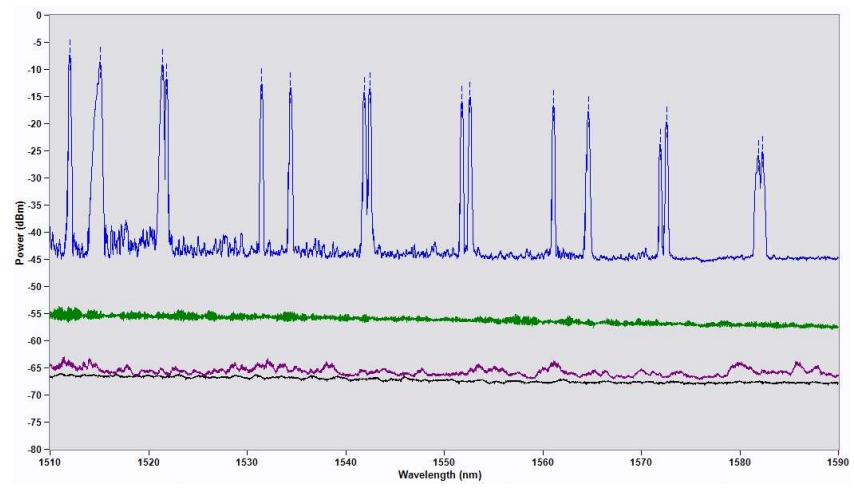

FIGURE 6. PEAK DETECTION AND CONFIGURATION INTERFACE.

Only a single channel (top channel) is active in this figure that shows pairs of strain and temperature compensation peaks. The peak location is identified and recorded for comparison to baseline values.

\section{Strain Calculations}

Changes in strain at the fiber Bragg grating (FBG) and along the fiber optic line cause the frequency of the peak $\lambda_{b}$ to shift by $\Delta \lambda\left(=\lambda_{b}-\lambda_{0}\right)$ which is used to calculate strain and ultimately the load. The strain sensors are sensitive to temperature changes and include temperature compensation due to changes in material thermal expansion (see Equation 1) and thermal sensitivity of the fiber optic cable (included in Equation 2).

$$
\mu \varepsilon_{T}=\left(C T E_{S}-C T E_{T}\right) \frac{\left(\Delta \lambda / \lambda_{0}\right)_{T}}{S_{T}}
$$

The thermal expansion causes a change in micro-strain $\left(\mu \varepsilon_{T}\right)$ that is the strain induced by thermal expansion differences between the sensor and the test article and depends on the coefficient of thermal expansion for the strain sensor $\left(C T E_{S}\right)$, the coefficient of thermal expansion for the test article $\left(C T E_{T}\right)$, the shift 
in wavelength from the nominal value $(\Delta \lambda)$, the nominal wavelength $\left(\lambda_{0}\right)$, and the temperature sensitivity that relates changes in wavelength to changes in micro-strain $\left(S_{T}\right)$. One of the most important advantages of FBG sensors is the direct relation between the Bragg wavelength and the fiber strain, which makes absolute measurements of the strain possible. The shift in the Bragg wavelength $(\Delta \lambda)$ can be observed and related to strain $\mu \varepsilon$ as shown in Equation 2.

$$
\mu \varepsilon=10^{6}\left[\frac{\left(\Delta \lambda / \lambda_{0}\right)_{S}-\left(\Delta \lambda / \lambda_{0}\right)_{T}}{F_{G}}\right]-\mu \varepsilon_{T}
$$

Equation 2 is the basis for the strain and load measurements used in this analysis. The source of temperature compensation $\left(\Delta \lambda / \lambda_{0}\right)_{T}$ is a series of FBGs on the fiber optic line that is not purposefully attached directly to a surface although bonding to the polyurethane coating may occur. In this disconnected condition, only fluctuations in load affect the probe location because the temperature effects are removed. The deformation due to changes in load produces a strain in the tendon wall. Using Hooke's law and compensating for temperature, a load is calculated from the strain data according to Equation 3.

$$
F=\mu \varepsilon E A
$$

In this case $E$ is the Young's Modulus and $A$ is the cross-sectional area of the test article. The load $F$ is monitored in units of kips $\left(=1000 l b_{f}\right)$ on the TLP to ensure that the pilings are not pulled out due to over-pull or the connectors are not unlatched due to under-tension. The load monitoring is especially critical during drilling rig loading and movement across the platform where up to a million pounds of additional weight is supported.

\section{Fiber Optic Sensor Description}

Fiber optic sensors have many different configurations and the fiber Bragg grating (FBG) is one of the most common. Other configurations could be similarly used for the work described in this project but FBGs were selected due to some key advantages. Some of these advantages are that a FBG has high sensitivity to temperature and strain [6]. A FBG contains gratings that are etched on an optical fiber to create periodic changes in the index of refraction as shown in Figure 7. The FBG sensor depicted in this figure consists of a single-mode optical fiber with gratings positioned at various locations along its length. The gratings are produced by doping the fiber with Germania and exposing it to an interference pattern of coherent light. Each grating is designed to reflect a certain frequency of light. Multiple such grating can be placed along a single fiber optic strand. The system is interrogated with a broadband light source and the multiple wavelength sensors within this source are detected [7].

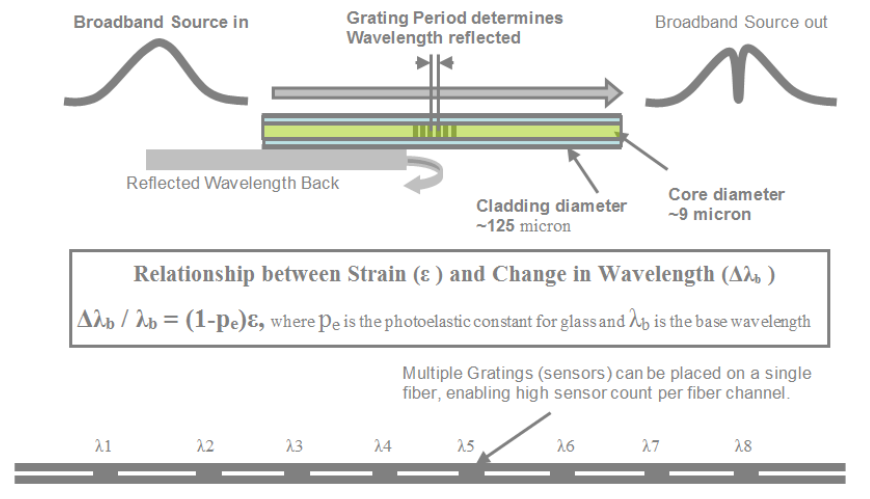

FIGURE 7. ILLUSTRATION OF A UNIFORM FIBER BRAGG GRATING WITH CONSTANT INDEX OF MODULATION AND PERIOD.

The FBG wavelength is sensitive to dimensional and temperature changes. The instrumentation senses the reflected frequencies and in turn determines the grating location and the dimensional change. Grating can be incorporated at any position along the fiber length. Changes in strain or temperature to which the optical fiber is subjected will consequently shift this Bragg wavelength, leading to a wavelength-encoded optical measurement. Table 1 details working ranges for typical FBG sensors.

TABLE 1. TYPICAL RANGES FOR FBG SENSORS.

\begin{tabular}{ll}
\hline Description & Typical Range \\
\hline Working wavelength range & $1520-1570 \mathrm{~nm}$ \\
Number of sensors along & \\
a single strand (FBG) & up to 32 \\
Resolution & $1 \mu \varepsilon$ \\
Accuracy & $5 \mu \varepsilon$ \\
Sampling Rate & up to $1 \mathrm{kHz}$ \\
Temperature range & -40 to $300 \mathrm{C}$ \\
\hline
\end{tabular}

Figure 8 shows a schematic of the typical response of a FBG when subjected to strain and resulting in a wavelength shift. By detecting this strain induced wavelength shift, a determination of absolute strain is made. Similarly, temperature induced shifts are detected resulting in absolute temperature.

Temperature compensation is provided by placing an additional FBG in the strain field area so that it is exposed to temper- 

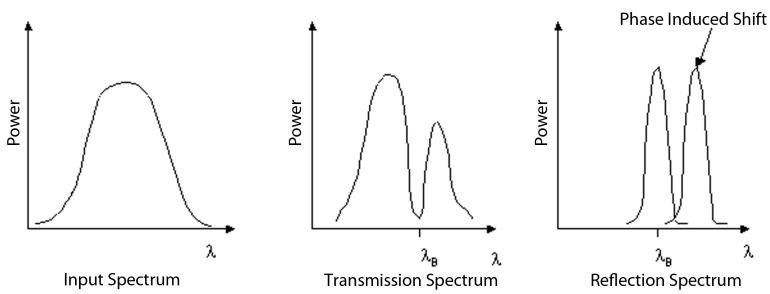

FIGURE 8. FUNCTIONAL PRINCIPLE OF A FIBER BRAGG GRATING.

ature but isolated from the strain field. The temperature induced shift is then subtracted from the strain measurement. Because multiple FBG sensors can be incorporated into a single fiber optic strand, each provides a unique reflected signal as shown in Figure 9.
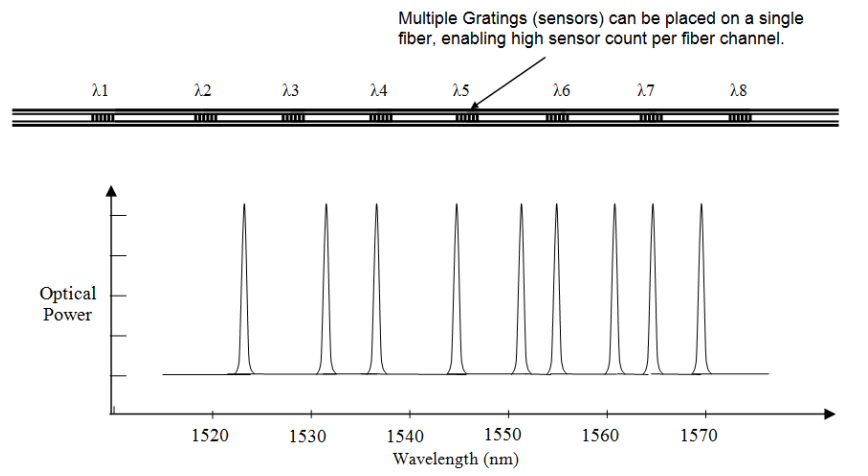

FIGURE 9. EXAMPLE OF MULTIPLE FBG SENSORS WITH UNIQUE REFLECTION CHARACTERISTICS.

Fiber optic sensors have several distinct advantages over conventional sensing systems. Some of the major advantages are as follows:

Are safe to install and operate

Low vulnerability to water ingress and "shorting"

Non intrusive with no penetrations required into pressure vessel as per convection electronic sensors

No electric current required

Are immune to electromagnetic interference (EMI)

Sensors are easily multiplexed

Entire sensor system has little or no impact on the physical structure

Are multifunctional - can measure strain, temperature, pressure and vibration

Have long-life
Contain compact electronics and support hardware

Have high strain sensitivity

Can provide continuous real-time monitoring

Many of the advantages make FBGs a natural choice for applications in remote deepwater locations [8] and extreme conditions such as this TLP load monitoring project.

\section{Calibration of Load Sensors}

The post-installed load sensors are installed on pretensioned systems and must be calibrated to current load conditions at steady-state conditions [9]. Web-based control and troubleshooting features were added to the software [10] to facilitate control [11-15] and monitoring [16-18] of the data acquisition system from a corporate network. For example, the calibration feature was one of the capabilities of the software in the web interface and makes it possible for the operators to calibrate the load values after installation of the Trident Monitoring System. The monitoring system includes interfaces to allow access from a corporate network as well as a distributed control system as shown in Figure 10.

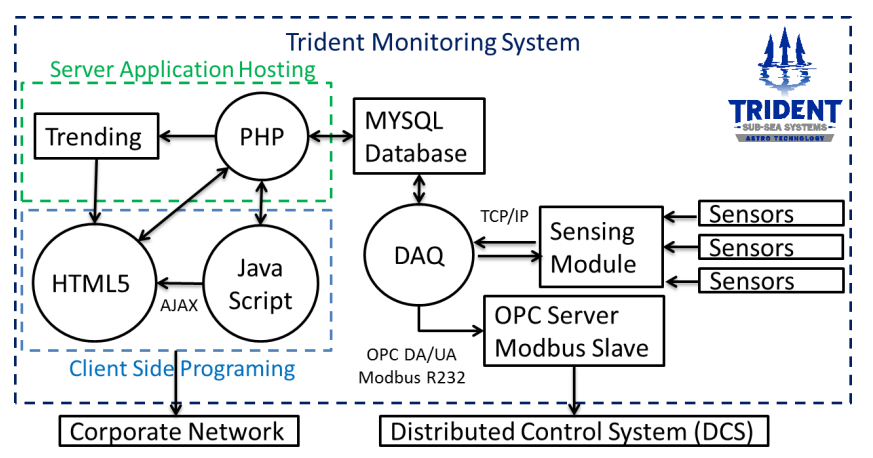

FIGURE 10. PEAK DETECTION AND CONFIGURATION INTERFACE.

The sensing module simultaneously interrogates multiple channels or fiber optic lines where the sensors are installed. In this case, the four tendons of the TLP are on a separate channel each. The sensing module communicates with the data acquisition (DAQ), historian (MySQL database), OPC server, and Modbus slave to make the data accessible for web access and industrial system integration.

\section{TEST RESULTS AND DISCUSSION}

In addition to the fiber optic sensors, four resistive (conventional) strain gauges were attached directly to the test articles. The strain gauges were oriented to measure uniaxial strain on 
the two 36 inch specimens. The location of the sensors was in a region near the fiber optic strain gauge section so as to produce nearly equivalent results. The location matched the strain field of that analyzed (by finite element analysis) for the mid pipe section containing the fiber optic sensors. The strain gauges were placed at $0,90,180$, and 270 degree azimuth to detect all of the bending modes and stress and compression of the article.

The fiber optic sensors included temperature compensation to correct the raw wavelengths in the calculation of strain. To ensure valid test results, a constant temperature environment was attempted during test runs. For any variation in the temperature, a continuous record of the temperature was collected during testing to provide temperature compensation for the sensors and data acquisition variations. Sensors were placed in pairs and positioned to avoid overlap of the peak wavelength values. As the strain increased, the peak wavelength associated with the strain gauge increased and the strain decreased when the strain dropped. The position of the unstrained peaks was chosen to avoid possible overlap of the peak values during normal operating ranges.

\section{4-Point Bending Test}

In the bending test, the sample pipe was pulled from the both ends at $280 \mathrm{kips}(1 \mathrm{kip}=1000 \mathrm{lbs})$ and was held for $5 \mathrm{~min}$ resulting in a bending force in the sensor locations. The 4-point bending test was performed on the test article as shown in Figure 11. The pipe was placed in the test fixture and tested with pipe at 0 degree azimuth facing up. The test was then repeated with rotated pipe and at 90, 180, and 270 degree azimuth after cycles of that lasted approximately 15 minutes.

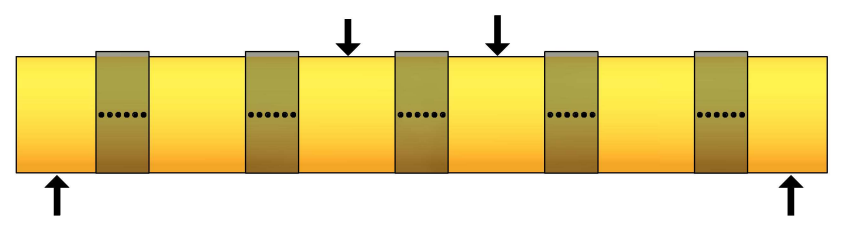

FIGURE 11. BENDING TEST WITH LOADS AT FOUR POINTS.

A direct comparison between the fiber optic sensors and resistive strain gauges shows excellent agreement as shown in Figure 12. It is noted that an error in the software configuration caused the $270^{\circ}$ sensor measurement to report bad values during the last of four bend tests on the fourth subplot. It is also noted that the strain recorded by the FBG sensor was less than that recorded by the resistive strain gauges. This occurs because the clamp serves as an extensometer to transfer strain from the pipe to the FBG sensors and as a result, the FBG sensors do not measure the actual strain directly. In the case of the compression and tension testing, an additional fiber optic sensor was attached directly to the surface of the pipe for verification purposes.

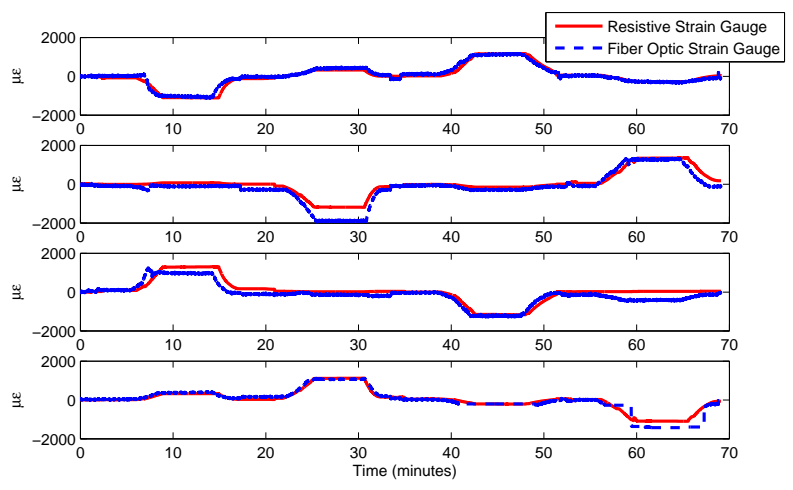

FIGURE 12. RESULTS OF THE 4-POINT BENDING TESTS WITH RESISTIVE AND FBG SENSORS.

One aspect of the comparison was the time stamping of the data acquisition so direct measurement comparisons could be made between the fiber optic gauges and the resistive gauges. Without the time stamps, the resistive strain gauge data at four points were synchronized for the results provided by each test article by aligning the leading edges of the initial peaks.

\section{Tension Test}

Tension loading was achieved by pulling the test article in uniaxial tension to a strain level of $70 \%$ of yield stress in tension. The strain levels were recorded and repeated through a number of cycles with equivalent strain level in compression (see Figure 13). The tension cycle was repeated for a total of ten cycles for first a slow rate of change followed by ten cycles of a fast rate of change. Testing was conducted at a strain rate of one inch per minute and then at the completion of the cycle tests the "at rest" strain values were recorded. Any relaxation effects were observed by recording the data for one hour following the stress and compression tests. The final values after the stress relaxation were then compared to the data from pre-testing. The entire test sequence was repeated again with a reduced strain rate of 0.1 inch per minute which is referred to as the fast rate of change tests.

In both tension and compression tests the load was increased up to 1000 kips and was held up to $5 \mathrm{~min}$. Each experiment was repeated 10 times to ensure data consistency and to validate the sensor robustness for large cycles in the strain. Both tension and compression tests were performed in fast and slow rates. Results for the tension testing are shown in Figure 14

All sensors showed some level of inelastic deformation due 


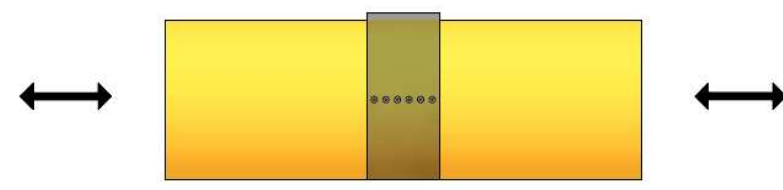

FIGURE 13. TENSION TESTING WITH SLOW (1"/MIN) AND FAST (0.1"/MIN) RATES OF CHANGE.

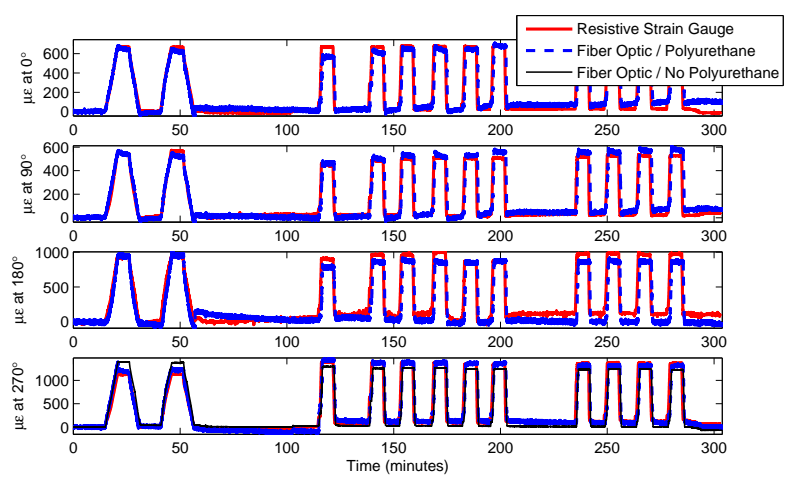

FIGURE 14. FIBER OPTIC AND RESISTIVE STRAIN GAUGES UNDER REPEATED TENSION LOAD CYCLES.

to the polyurethane coating used in the bonding and coating process. A comparison with the unbounded sensors in the fourth subplot of Figure 14 reveals that there is some hysteresis when compared with the pipe-bonded sensors. For sensors installed with a polyurethane coating, this implies that there is a settling period where the sensors may need to be recalibrated after initial cycles of operation. The recalibration is built into the software design to allow for adjustment of both the absolute load as well as the sensitivity of the load measurement to changes. To avoid recalibration concerns, a protective lubricant was applied to the sensors to prevent bonding of the sensors to the viscoelastic polyurethane encasement. This modification is expected to show improved performance for the sensor clamps installed on the TLP.

The sensors returned to pre-load conditions after the compression load was released demonstrating the ability of the sensors to withstand loads at least up to $70 \%$ of failure. The extensometer configuration of the clamps and polyurethane coating caused a slight lag in the strain readings during the load and relaxation periods. Note that the strain values continue to slightly decrease during the plateau period. The load sensitivity and relaxation time is nearly immediate for the resistive and FBG sensors attached directly to the pipe.

\section{Compression Test}

Compression loads were achieved by pushing the test article in uniaxial compression to a strain level of $70 \%$ of yield stress in compression. The strain levels were recorded and repeated through a number of cycles with equivalent strain levels at the tension tests. The compression cycle was also repeated for a total of ten cycles for first a slow rate of change followed by ten cycles of a fast rate of change. Testing was conducted at a strain rate of one inch per minute and then at the completion of the cycle tests the "at rest" strain values were recorded. Any relaxation effects were observed by recording the data for one hour following the stress and compression tests. The final values after the stress relaxation were then compared to the data from pre-testing. The entire test sequence was repeated again with a reduced strain rate of 0.1 inch per minute for the fast rates of change. As expected, the resistive strain gauge reading became negative during the compression testing as well as the FBG compressive readings on each of the four sensor stations as observed in Figure 15.

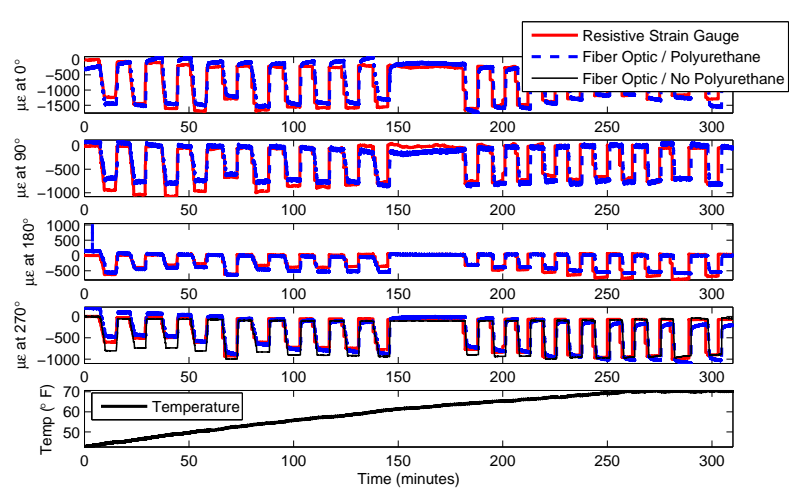

FIGURE 15. FIBER OPTIC AND RESISTIVE STRAIN GAUGES UNDER REPEATED COMPRESSION LOAD CYCLES.

The fast and slow rates of compression load had little effect on the outcome of the sensors that were attached directly to the pipe. The fast compression cycles did have a more pronounced effect on the clamp sensors with polyurethane coating as shown in Figure 15. These tests reveal that the installed sensors will have varying levels upon initial installation due to their configuration as extensometers of strain. After calibration, the sensors will be adjusted to report the same base-line level of load and have equal sensitivity to load changes. It appears that these calibration values cannot be predicted a priori but likely depend on a number of factors related to construction and installation.

Regardless of the rate of strain, it was observed that the sensors responded nearly the same in the two cases. The figures show relaxation to original values after each cycle and the need for calibration when initially installed. The sensors showed good 
repeatability and relaxation to original values.

Load values obtained from the fiber optic sensors were compared with the ones from conventional strain gauge sensors. Good agreement was found between the two data sets with the multiplication factors to account for the polyurethane extrusion effect. To check the polyurethane extrusion effect on the data reading, a sensor set was attached to the pipe body without the protection of external coating material. The results in Figure 15 show that the aforementioned sensor set is much more sensitive over external forces than the ones encapsulated in the polyurethane which require a multiplier factor.

It was concluded that installation on external clamps and encapsulating the sensors in polyurethane decreases the strain sensor sensitivity over external forces. To overcome this, a multiplication factor was added to the calculations and its optimal value was found from the aforementioned tests. This additional factor compensates for the extensometer nature of the clamp including the polyurethane effect by increasing sensitivity of the load values due to changes in the wavelength values. After the installation of the fiber optic strain sensors, the gauges will be calibrated with historical and current available values from operating load cells before the aging system is replaced.

\section{Button Test}

A button pull test is currently slated for completion but final results have not yet been obtained. The button test is a final evaluation of the test articles to determine the bonding strength up to failure. For this test, six buttons will be prepared from each of four surface preparation methods used in four preliminary tank tests for a total of twenty-four samples. The tests will also include an additional six buttons from each of the samples that underwent stress testing in the bending, compression, and tension cycles. The button pull tests will measure the load of all samples to failure as shown in Figure 16.

\section{RECOMMENDATIONS}

Significant progress and technology advancement was achieved on this TLP monitoring project. There were several additional advancements that should be pursued, primarily in the post installation area [7]. A Joint Industry Project (JIP) was founded to address these issues along with a multitude of other deepwater innovations. The Clear Gulf JIP relies on expertise provided by subject matter experts from the oil and gas industry in conjunction with technology experts from NASA. Much of the development work for Clear Gulf JIP is currently in progress at NASA facilities and at Astro Technology in Houston, Texas.

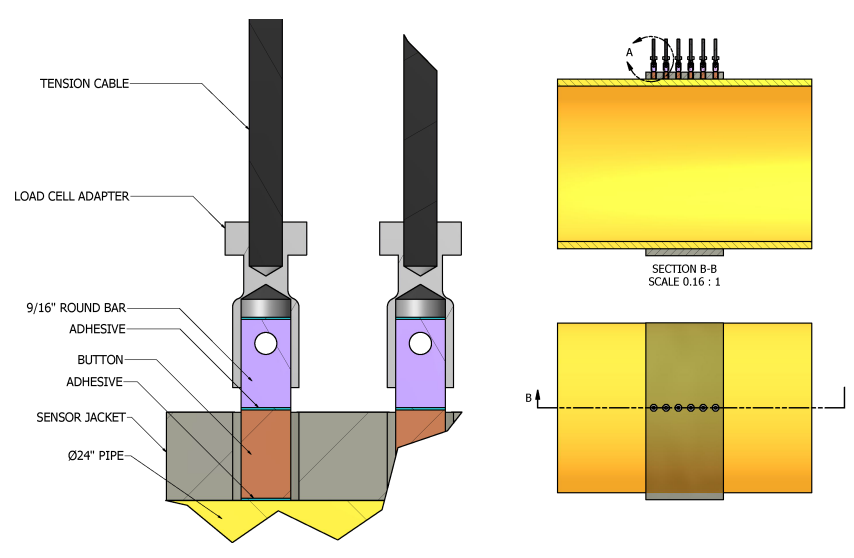

FIGURE 16. BUTTON PULL TEST TO EVALUATE BONDING STRENGTH UP TO FAILURE.

\section{CONCLUSIONS}

As deepwater fields in the Gulf of Mexico, West Africa, offshore Brazil, and elsewhere are developed it becomes increasingly important to detect crucial engineering properties of subsea equipment and environmentally induced conditions. Technology described in this paper provides actual operational information and data for improved design and structural integrity.

A new innovative post installed sensor clamp as been developed and intergrated into an advanced monitor system to accurately measure (in real-time) strain, load, and temperature. The stress tests confirmed that the fiber optic sensors are adequately bonded to test articles in underwater conditions. The stress testing also confirmed that the fiber optic sensors function as designed under loads of at least up to $70 \%$ of the failure strain with fast or slow rates of change. The sensors returned to the prestress state after the loadings and were in agreement with the strain gauge sensors that were installed for independent verification. The test results provided the calibration data for the sensors that will be deployed on the TLPs.

\section{REFERENCES}

[1] Brower, D., Prescott, C., Zhang, J., Howerter, C., and Rafferty, D. "Real-time flow assurance monitoring with nonintrusive fiber optic technology".

[2] Prescott, C., Zhang, J., and Brower, D. "An ambient pressure insulated lng pipeline for subsea environments".

[3] Brower, D. V. "Structural properties measurements in deepwater oil and gas fields using an advanced fiber-optic sensor monitoring system".

[4] Brower, D. V., and Prescott, C. "Real time subsea monitoring and control smart field solutions".

[5] Brower, D. V. "Real-time fatigue monitoring of deepwater drilling and oil production risers using fiber-optic sensors". 
[6] Kersey, A., 2000. "Optical fiber sensors for permanent downwell monitoring applications in the oil and gas industry". IEICE Trans. Electron., E83-C(3), March, pp. 400404.

[7] Brower, D., Hedengren, J., Loegering, C., Brower, A., Witherow, K., and Winter, K., 2012. "Fiber optic monitoring of subsea equipment". In Ocean, Offshore \& Arctic Engineering OMAE, no. 84143.

[8] Hedengren, J., and Brower, D., 2012. "Advanced process monitoring of flow assurance with fiber optics". In AIChE Spring Meeting.

[9] Kelly, J., and Hedengren, J., 2013. "A steady-state detection (SSD) algorithm to detect non-stationary drifts in processes". Journal of Process Control.

[10] Hedengren, J., 2013. APMonitor Modeling Language. http://APMonitor.com.

[11] Hedengren, J., and Edgar, T., 2008. "Approximate nonlinear model predictive control with in situ adaptive tabulation". Computers and Chemical Engineering, 32, pp. 706714.

[12] Soderstrom, T., Zhang, Y., and Hedengren, J., 2010. “Advanced process control in Exxonmobil Chemical Company: Successes and challenges". In AIChE National Meeting.

[13] Hedengren, J., 2013. Optimization and Analytics in the Oil and Gas Industry. Springer-Verlag Berlin Heidelberg, ch. Advanced Process Monitoring, p. submitted.

[14] Powell, K., Hedengren, J., and Edgar, T. "Dynamic optimization of a solar thermal energy storage system over a 24 hour period using weather forecasts".

[15] Jacobsen, L., Spivey, B., and Hedengren, J. "Model predictive control with a rigorous model of a solid oxide fuel cell".

[16] Hedengren, J., and Edgar, T., 2006. "Moving horizon estimation - the explicit solution". In Proceedings of Chemical Process Control (CPC) VII Conference.

[17] Spivey, B., Hedengren, J., and Edgar, T., 2009. "Monitoring of process fouling using first-principles modeling and moving horizon estimation". In Proc. Applications of Computer Algebra (ACA) Conference.

[18] Spivey, B., Hedengren, J., and Edgar, T., 2010. "Constrained nonlinear estimation for industrial process fouling". Industrial \& Engineering Chemistry Research, 49(17), pp. 7824-7831. 